\title{
Reoperações após cirurgia de Bentall-De Bono para ectasia ânulo-aórtica
}

\author{
Renato A. K. KALIL*, Ricardo GARCIA-MACEDO*, Paulo Roberto PRATES*, Fernando A. LUCCHESE*, \\ João Ricardo SANT'ANNA*, Raul F. A. LARA*, Altamiro R. COSTA*, Nestor S. DAUDT*, Edemar M. PEREI- \\ RA*, Ivo A. NESRALLA*
}

RBCCV 44205-54

KALIL, R. A. K.; GARCIA-MACEDO, R.; PRATES, P. R.; LUCCHESE, F. A.; SANT'ANNA, J. R.; LARA, R. F. A.; COSTA, A. R.; DAUDT, N. S.; PEREIRA, E. M.; NESRALLA, I. A. - Reoperaçōes após cirurgia de Bentall-De Bono para ectasia ânulo-aórtica. Rev. Bras. Cir. Cardiovasc., 3(2): 93-100. 1988.

RESUMO: Complicaçōes tardias após substituição da aorta ascendente e valva aórtica pela técnica de enxerto valvulado de Bentall-De Bono podem constituir sério problema cirúrgico. Condutas nestas situaçōes não estão padronizadas. Entre 37 pacientes operados, no período de janeiro de 1976 e dezembro de 1986, ocorreram complicaçōes tardias necessitando tratamento cirúrgico em 5 (13.5\%) casos. Alguns deles apresentaram mais de uma alteração. Estas foram: rotura de válvula biológica (dura-máter), pertuito peritubular na anastomose proximal, pseudo aneurisma em sutura do óstio coronariano esquerdo, deiscência da sutura proximal do tubo, hemólise e endocardite infecciosa localizada no enxerto de Dacron. Um paciente apresentou embolizaçāo sistêmica por vegetaçâo. $O$ tratamento cirúrgico consistiu na substituição do enxerto, preservando-se a prótese, nos 2 casos de endocardite infecciosa. As duas biopróteses de dura-máter rotas foram substituidas por próteses metálicas de disco, preservando-se o tubo implantado e abordando-se a prótese através de incisão longitudinal no mesmo. As situaçōes de deiscência de sutura e pseudo-aneurisma foram corrigidas mediante sutura direta dos pertuitos localizados. Ocorreu 1 óbito $(20 \%)$ no pós-operatório imediato à reoperaçāo, em paciente com endocardite infecciosa por fungo (Aspergillus), decorrente de sangramento incontrolável. Os demais 4 pacientes receberam alta hospitalar, após recuperação sem intercorrências, no 9: dia de pós-operatório, em 3 casos, e no 22:, no caso de endocardite. Como complicação tardia, tivemos 1 caso de persistência do pertuito peritubular em comunicação com o óstio coronariano esquerdo. causando insuficiência aórtica (IAO) e hemólise leve residuais. Houve 1 óbito tardio, por hemorragia, durante procedimento cirúrgico não cardiaco. Complicaçōes relacionadas a infecção, deiscência de suturas, ou degeneração de bioprótese ocorrem com certa freqüência na evolução a longo prazo deste tipo de correção cirúrgica. $\mathrm{O}$ tratamento pode ser realizado com risco aceitável e visar apenas à intervenção sobre o defeito apresentado, conservando-se as demais estruturas. É recomendável a utilização de prótese metálica, como primeira opção, para evitar os problemas degenerativos dos materiais biológicos.

DESCRITORES: Bentall-De Bono, operaçāo de, reoperação.

\section{INTRODUÇĀO}

O desafio cirúrgico representado pela ectasia ânuloaórtica passou a ser adequadamente enfrentado após a proposição de BENTALL-DE BONO ' para substituição da aorta ascendente por enxerto composto de tubo e prótese valvular. $\mathrm{Na}$ década passada, vários Serviços optaram pela utilização dessa técnica, com bons resulta$\operatorname{dos}^{6.9 .10}$. Nossa experiência iniciou-se em 1976, tendo sido já publicados os resultados iniciais ${ }^{7,9}$. Poucos têm

Trabalho realizado no Instituto de Cardiologia do Rio Grande do Sul. Fundaçăo Universitária de Cardiologia. Porto Alegre, RS, Brasil

Brasil.

Apresentado ao 15: Congresso Nacional de Cirurgia Cardiaca. Rio de Janeiro, RJ, 8 e 9 de abril, 1988.

- Do Instituto de Cardiologia do Rio Grande do Sul. Fundação Universitária de Cardiologia

Endereço para separatas: Renato Kalil. Av. Princesa Isabel, 195. 90620 Porto Alegre, RS, Brasil. 
KALIL, R. A. K.; GARCIA-MACEDO, R.; PRATES, P. R.: LUCCHESE, F. A.; SANT ANN, J. R.: LARA, R. F. A.; COSTA, A. R.: DAUDT, N. S.: PEREIRA, E. M.: NESRALLA, I. A. - Reoperaçōes após cirurgia de Bentall-De Bono para ectasia ânulo-aórtica. Rev. Bras. Cir. Cardiovasc., 3(2): 93-100, 1988.

TABELA 1

SUMARIO DOS CASOS REOPERADOS

\begin{tabular}{|c|c|c|c|c|c|c|c|c|}
\hline CASON: & $D A D E$ & SEXO & ETIOLOGIA & $D A T A \cap C I A$. & DATA REOP & PATOLOGIA CIRUARGICA & TRATAMENTO & EVOLUCAOAO \\
\hline$\stackrel{1}{\mathrm{GGG}}$ & 43 & M & $\begin{array}{l}\text { Necrose cistica } \\
\text { da média }\end{array}$ & out: 77 & abr. 80 & $\begin{array}{l}\text { - Rotura do tecido de } \\
\text { dura-mater }\end{array}$ & $\begin{array}{l}\text { - Substituiçào da prótese } \\
\text { valvular por modelo } \\
\text { Lillehei-Kaster }\end{array}$ & $\begin{array}{l}\text { Alta 9: dia p.o } \\
\text { Atual: IC classe II }\end{array}$ \\
\hline $\begin{array}{c}2 \\
\mathrm{MN}\end{array}$ & 63 & M & $\begin{array}{l}\text { Necrose cistica } \\
\text { da média }\end{array}$ & nov. 77 & set. 78 & $\begin{array}{l}\text { - Rotura do tecido de } \\
\text { dura-máter } \\
\text { - Pertuitos peritubulares } \\
\text { - Hernatoma organizado } \\
\text { - Aneurisma a femoral }\end{array}$ & $\begin{array}{l}\text { - Ressutura dos pertuitos } \\
\text { - Substituiçáo da prótese } \\
\text { valvular por modelo } \\
\text { Björk-Shiley }\end{array}$ & $\begin{array}{l}\text { Alta } 9: \text { dia p.o } \\
\text { Obito } 10 \text { : mês p.o. } \\
\text { por hemorragia }\end{array}$ \\
\hline $\begin{array}{l}3 \\
\text { GAS }\end{array}$ & 39 & $M$ & $\begin{array}{l}\text { Dissecção aórtica } \\
\text { tipo II, Insuf. aórtica. } \\
\text { El }\end{array}$ & ago 80 & jan 81 & $\begin{array}{l}\text { - Vegetaçóes na superficie } \\
\text { interna do enxerto } \\
\text { - Embolia sistêmica }\end{array}$ & $\begin{array}{l}\text { - Substituido o enxerto } \\
\text { tubular, preservando-se } \\
\text { a válvula }\end{array}$ & $\begin{array}{l}\text { Óbito } 24 \text { h p.o por } \\
\text { hemorragia }\end{array}$ \\
\hline $\begin{array}{c}4 \\
\text { AMNP }\end{array}$ & 43 & $\mathrm{~F}$ & $\begin{array}{l}\text { Necrose cistica da } \\
\text { média (aortoplastia } \\
\text { prévia) }\end{array}$ & dez. 81 & set. 82 & $\begin{array}{l}\text { - Vegetaçōes na superficie } \\
\text { interna do enxerto }\end{array}$ & $\begin{array}{l}\text { - Substituidos o enxerto } \\
\text { tubular e a bola de } \\
\text { silicone da prótese } \\
\text { valvular }\end{array}$ & $\begin{array}{l}\text { Alta } 22 \text {. dia p.o. } \\
\text { Atual: IC classe II }\end{array}$ \\
\hline $\begin{array}{c}5 \\
\text { OSB }\end{array}$ & 44 & M & $\begin{array}{l}\text { Necrose cistica } \\
\text { da média }\end{array}$ & jul. 83 & fev. 85 & $\begin{array}{l}\text { - Deiscências das suturas } \\
\text { do óstio coronariano E } \\
\text { e do enxerto proximal } \\
\text { - Hemolise } \\
\text { - Pseudo-aneurisma }\end{array}$ & $\begin{array}{l}\text { - Ressutura do óstio } \\
\text { coronariano }\end{array}$ & $\begin{array}{l}\text { Alta } 9 \text { dia p.o. } \\
\text { Atual: IC classe II } \\
\text { hemólise }\end{array}$ \\
\hline
\end{tabular}

$E I=$ Endocardite infecciosa

IC = Insuficiēncia cardiaca

sido os relatos de complicações tardias ${ }^{2}$. 3. 4. 8 , que, certamente, ocorrem em certo número, bem como das soluçōes encontradas. Este trabalho tem por objetivo relatar os casos, de nossa experiência, em que foi necessária reoperação para correção de complicaçōes pós-operatórias tardias, bem como apresentar as técnicas cirúrgicas empregadas.

\section{CASUISTICA E MÉTODOS}

No periodo de 11 anos, entre janeiro de 1976 e dezembro de 1986, 37 pacientes foram submetidos a implante de tubo valvulado aórtico, pela técnica de Bental-De Bono, para tratamento de ectasia ânulo-aórtica. A técnica cirúrgica, bem como o material empregado já foram relatados anteriormente ${ }^{7} \cdot 9$. Nesse intervalo de tempo, $5(13,5 \%)$ pacientes vieram a apresentar complicaçōes pós-operatórias tardias, necessitando correçāo cirúrgica (Tabela 1). Alguns pacientes apresentaram mais de um defeito passivel de correção. Para melhor entendimento, descreveremos os casos de forma individual

Caso 1 - GGG, 43 anos, branco, masculino, operado em outubro de 1977 devido a ectasia ânulo-aórtica conseqüente a necrose cística da média; teve implantado um tubo de Dacron $30 \mathrm{~mm}$ com bioprótese de dura-máter. Em abril de 1980 (2 anos e 5 meses p.o.), apresentou sinais de insuficiência aórtica severa, necessitando nova cirurgia. Esta foi realizada sob circulação extracorpórea convencional, canulando-se átrio direito, artéria femoral e átrio esquerdo para aspiração. Foi encontrada a parede aórtica aderida externamente sobre o tubo, não havendo formação de endotélio na face interna do mesmo. A bioprótese estava bem implantada e endotelizada, mas mostrava orificio em forma de fenda ampla por rotura do tecido na zona de inserção no anel (Figura 1). Foi abordada por incisão longitudinal do tubo de Dacron e retirada por dentro do mesmo, seccionando-se 0 anel de tecido de maneira a liberar a estrutura da bioprótese e manter íntegra a sutura proximal do conjunto tubo-bioprótese. Em seu lugar, foi implantada prótese metálica de disco modelo Lillehei-Kaster $\mathrm{n}: 18 \mathrm{M}$, fixada mediante pontos isolados em $U$ de poliéster $2-0$, sobre a sutura prévia. A incisāo do enxerto foi suturada, juntamente com a parede aórtica, com fio de polipropileno 4-0, de forma contínua. O periodo de pós-operatório imediato foi sem intercorrências e o paciente recebeu alta hospitalar no 9: dia, tendo evolução posterior satisfatória, em classe funcional II de insuficiência cardiaca.

Caso 2-MN, 63 anos, branco, masculino, portador de ectasia ânulo-aórtica por necrose cística da média. submetido a implante de tubo valvulado, em novembro 1977, necessitou reoperação em setembro 1978 (10 meses de pós-operatório). A angiografia demonstrava insu ficiência aórtica e pseudo-aneurisma (Figura 2). A técnica de abordagem foi semelhante à descrita acima. Apresentava rotura do tecido da bioprótese de dura-máter e junto às 2 hastes correspondentes (Figura 2), pertuitos 
KALIL, R. A. K.; GARCIA-MACEDO, R.; PRATES, P. R.; LUCCHESE, F. A.; SANT'ANN, J. R.; LARA, R. F. A.; COSTA, A. R.; DAUDT, N. S.; PEREIRA, E. M.; NESRALLA, I. A. - Reoperaçōes após cirurgia de Bentall-De Bono para ectasia ânulo-aórtica. Rev. Bras. Cir. Cardiovasc., 3(2): 93-100, 1988.

peritubulares de cerca de $3 \mathrm{~mm}$ nas suturas proximal e distal do tubo, hematoma organizado no espaço entre a parede aórtica e o tubo de Dacron, com cerca de $15 \mathrm{~mm}$ em espessura, e aneurisma sacular, provavelmente micótico na artéria femoral esquerda. Foram retirados os trombos organizados, suturados diretamente os pertuitos, corrigido o aneurisma micótico por arterioplastia, retirada a bioprótese como descrito no caso 1 e implantada prótese metálica de disco, modelo BjörkShiley tamanho 25 , fixada diretamente na face interna do tubo de Dacron, no espaço entre a sutura prévia e os óstios coronarianos. O tubo foi ressuturado com fio de polipropileno 5-0 e aberta a pinça aórtica para revisão da hemostasia. Recuperados os batimentos cardíacos, foi procedida a aortografia sobre o enxerto e descontinuada a circulação extracorpórea. O período de pós-operatório imediato transcorreu sem complicações e o paciente recebeu alta hospitalar no 9: dia. No 10 : mês de pós-operatório, procurou o hospital com queixa de dor torácica e apresentando hemoptise. O tempo de protrombina era $12,5 \%$ (46s). Foi indicada internação hospitalar, que não pôde ser efetuada por falta de vaga, sendo encaminhado a outra Instituiçāo, onde foi hospitalizado. Nessa internação, durante procedimento cirúrgico exploratório sobre o mediastino, apresentou sangramento incontrolável, evoluindo para óbito.

Caso 3 - GAS, 39 anos, branco, masculino, apresentava dissecção aórtica tipo Il com insuficiência aórtica e endocardite infecciosa. Foi submetido a implante de

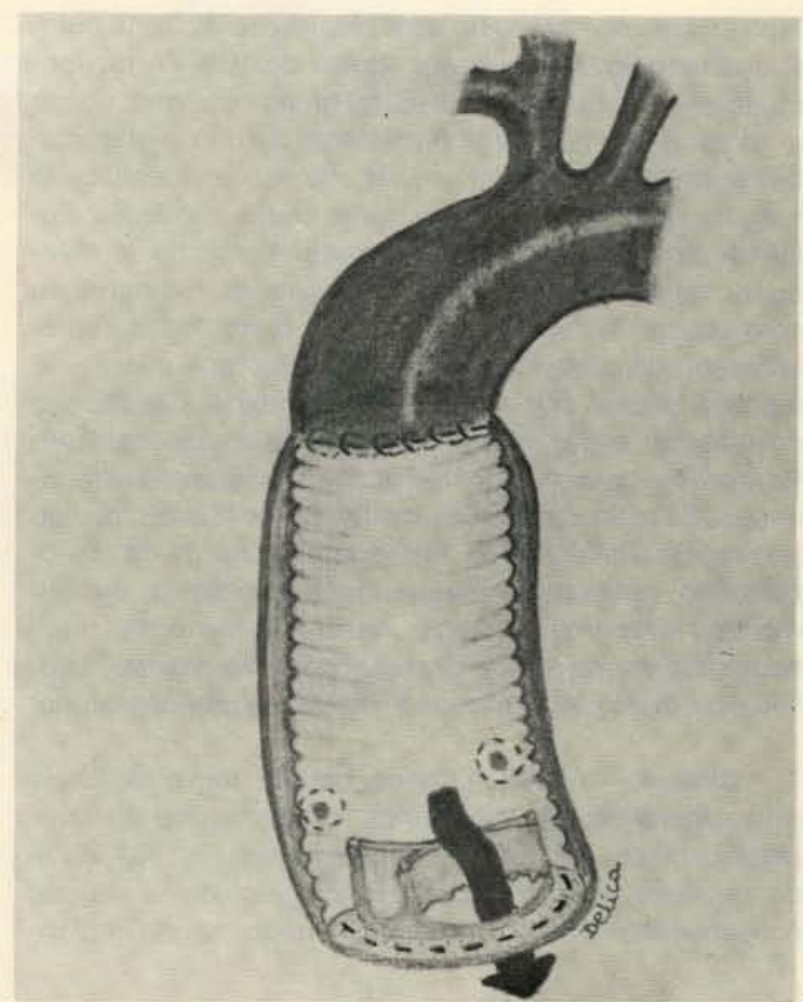

Fig. 1 - Representação esquemática dos defeitos encontrados no caso 1. Rotura em forma de fenda no tecido da bioprótese de duramáter. Parede aórtica aderida externamente ao enxerto tubular Ausência de endotélio na superficie interna do enxerto.

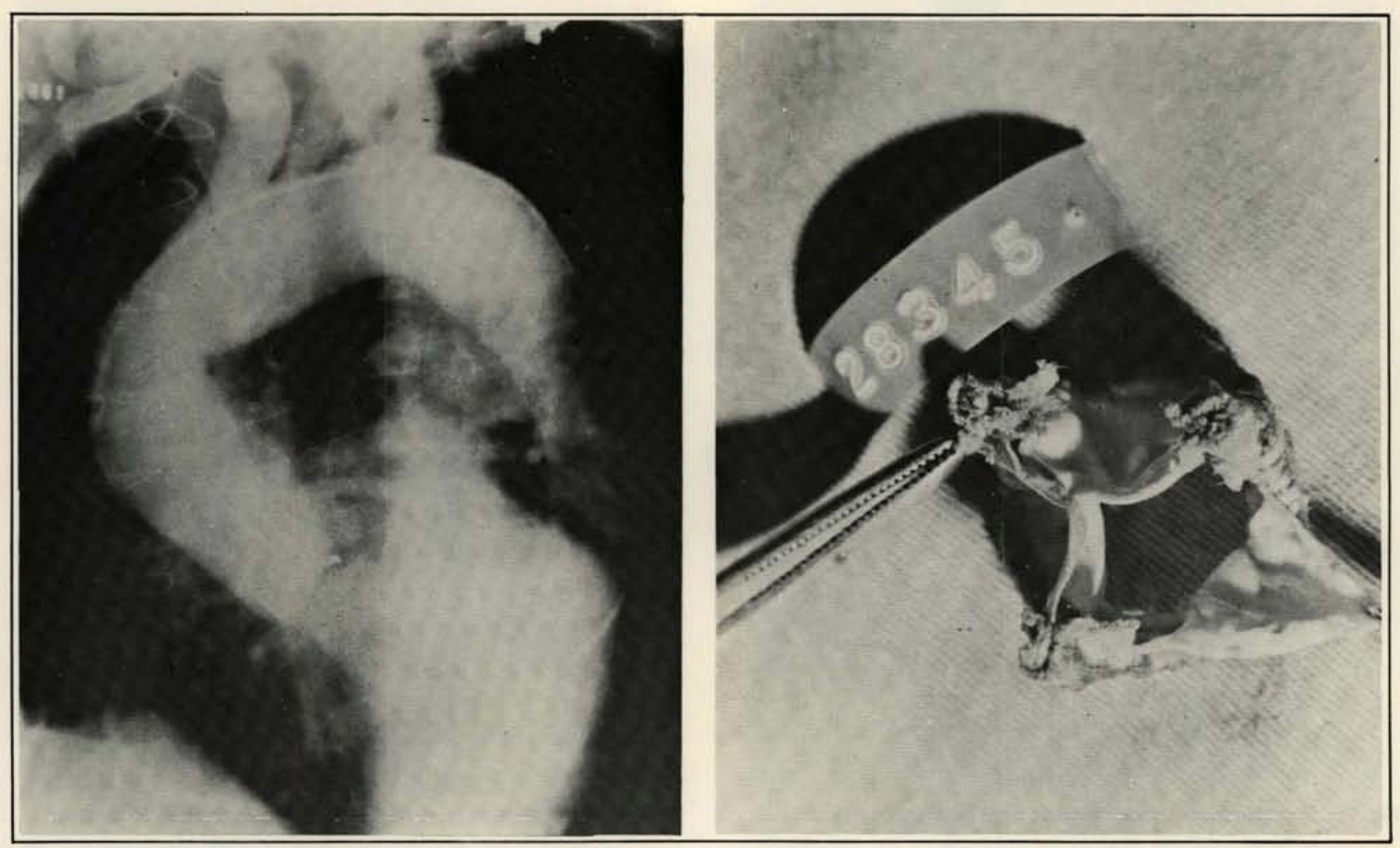

Fig. 2 - (Á esquerda): Angiografia demonstrando insuficiência aórtica a pseudo-aneurisma. (Á direita): bioprótese de dura-máter retirada, mostrando rotura do tecido. 
KALIL, R. A. K.; GARCIA-MACEDO, R.; PRATES, P. R.; LUCCHESE, F. A.; SANT'ANN, J. R.; LARA, R. F. A.; COSTA, A. R.; DAUDT, N. S.; PEREIRA, E. M.; NESRALLA, I. A. - Reoperaçōes após cirurgia de Bentall-De Bono para ectasia ânulo-aórtica. Rev. Bras. Cir. Cardiovasc., 3(2): 93-100, 1988.

tubo de Dacron composto com bioprótese de aorta heteróloga modelo Hancock, em agosto de 1980. A recuperação pós-operatória imediata foi muito boa, mas voltou a apresentar hipertermia persistente devido a endocardite e embolia sistêmica por vegetação. Foi identificado fungo do gênero Aspergillus, como causa etiológica. Em janeiro de 1981, aos 5 meses de pós-operatório, foi levado, novamente, à cirurgia. Foi encontrada a bioprótese com aspecto normal. Havia focos de endocardite, representados por extensas vegetaçōes, na face interna do tubo de Dacron (Figura 3). Procedeu-se à substituição do mesmo, separando-o da bioprótese, cujo implante foi mantido, bem como a área proximal aos óstios coronarianos. Os tecidos aórticos mostravam-se friáveis, devido ao processo inflamatório. Nas primeiras horas de pós-operatório, apresentou sangramento excessivo, que se mostrou incontrolável após duas reintervençōes, originado da linha de sutura proximal do novo enxerto. Evoluiu para óbito nas primeiras 24 horas de pós-operatório.

Caso 4 - AMNP, 43 anos, branca, feminina, havia sido submetida, há vários anos, a aortoplastia e valvoplastia aórtica. Foi operada em dezembro de 1981, devido a ectasia ânulo-aórtica e insuficiência aórtica severa, conseqüentes a necrose cística da média, sendo implan-

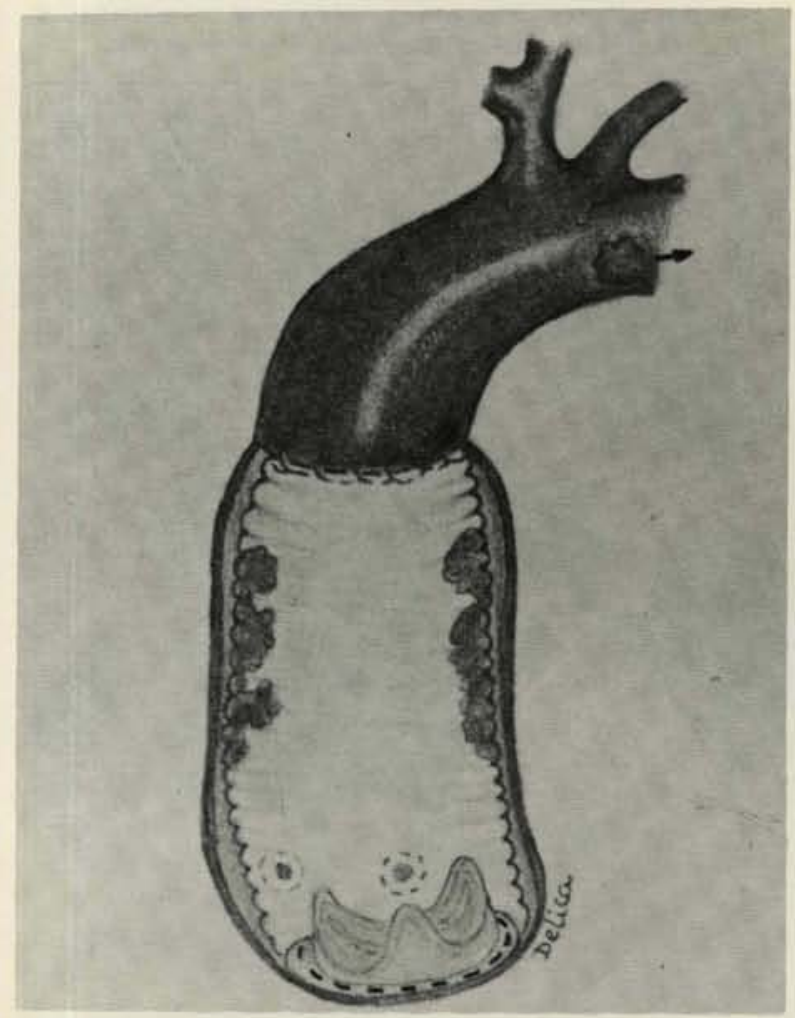

Fig. 3-Representação esquemática do aspecto cirúrgico referente ao Caso 3. Extensas vegetaçōes ocasionadas por endocardite infecciosa. (Aspergillus) na porção média do enxerto de Dacron, sem afetar a bioprótese de aorta heteróloga. tado tubo de Dacron, com prótese modelo Starr-Edwards. Em setembro de 1982, aos 9 meses de pós-operatório, foi, novamente, hospitalizada, por endocardite infecciosa. Não houve melhora clínica com a terapêutica antibiótica, persistindo a hipertermia e piora do estado geral, apesar das hemoculturas serem sempre negativas, impossibilitando a identificação do agente etiológico. Indicada a cirurgia, foi encontrado o tubo de Dacron revestido, internamente, por fina e frágil película amarelada, coberta por vegetaçōes pequenas, conferindo um aspecto rugoso à superfície interna do mesmo (Figura 4). A prótese estava livre de vegetaçōes, bem como a porção inicial do tubo, até pouco acima das anastomoses dos óstios coronarianos. Foram identificadas calcificações do anel aórtico nas áreas vizinhas à prótese. O tubo foi excisado, recortando-o acima dos óstios coronarianos, e implantado outro semelhante, com sutura proximal de fio poliester 3-0 ancorado em feltro de Teflon no remanescente do tubo primitivo. Foi feita sutura distal contínua com fio de polipropileno 3-0. $\mathrm{Na}$ oportunidade, foi substituída a bola de silicone da prótese valvular. A evolução pós-operatória foi favorável, recebendo alta hospitalar no $22^{\circ}$ dia, em boas condiçōes clínicas. Atualmente, leva vida praticamente normal, em classe funcional II (Critérios da New York Heart Association).

Caso 5 - OSB, 44 anos, branco, masculino, teve implantado enxerto composto de tubo de Dacron e próte-

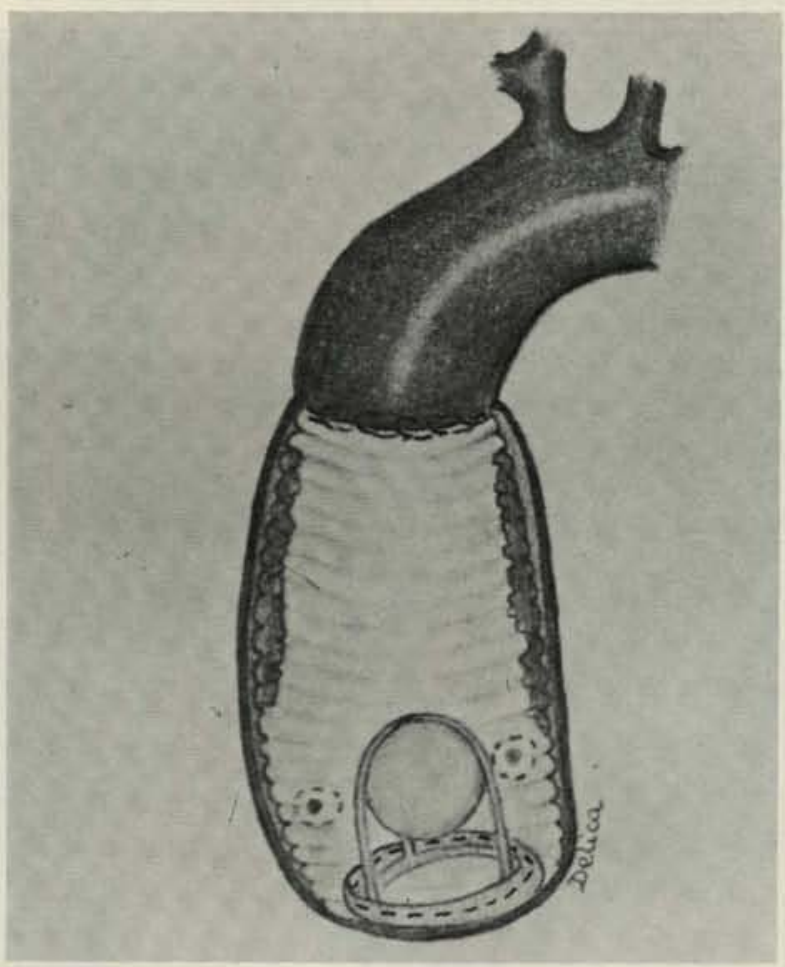

Fig. 4 - Representaçāo esquemática do aspecto cirúrgico do Caso 4. Enxerto tubular revestido internamente por fina e frágil pelicula coberta por pequenas vegetaçôes na porção média. Ausência de comprometimento da prótese pelo processo infeccioso. 
KALIL, R. A. K.; GARCIA-MACEDO, R.; PRATES, P. R.; LUCCHESE, F. A.; SANT'ANN, J. R.; LARA, R. F. A.; COSTA, A. R.; DAUDT, N. S.; PEREIRA, E. M.; NESRALLA, I. A. - Reoperaçōes após cirurgia de Bentall-De Bono para ectasia ânulo-aórtica. Rev. Bras. Cir. Cardiovasc., 3(2): 93-100, 1988.

se modelo Lillehei-Kaster em julho de 1983. Aos 19 meses do pós-operatório, em fevereiro de 1985, apresentava sinais clínicos de insuficiência aórtica moderada e quadro de hemólise intravascular severa, avaliada por critérios clínicos usuais ${ }^{5}$. A investigação demonstrou regurgitação paravalvular, tendo sido indicada cirurgia. Nesta, foram encontradas deiscências nas suturas do óstio coronariano esquerdo e da extremidade proximal do enxerto, determinando, assim, a existência de amplo pseudo-aneurisma entre o enxerto e a parede aórtica, com regurgitação através do mesmo, para a cavidade do ventrículo esquerdo (Figura 5). Considerou-se que a simples ressutura do óstio coronariano esquerdo seria suficiente para solucionar o problema, uma vez que o pertuito paraprotéico nāo era amplo, além de se situar na porção posterior, de difícil acesso. Através de incisāo longitudinal do enxerto, foi ressuturado o óstio coronariano com fio de polipropileno 4-0, ancorado em alguns feltros de Teflon. $O$ enxerto e parede aórtica foram suturados diretamente, o ar removido do coração, recuperados os batimentos cardiacos e terminada a cirurgią. Nāo ocorreram complicaçōes pós-operatórias significativas. Recebeu alta hospitalar no 9: dia. Por ocasião do primeiro controle ambulatorial, entretanto, notou-se, novamente, a presença de sopro diastólico de insuficiência aórtica e sinais de hemólise intravascular leves. Permaneceu em observação por alguns meses, optando-se por não realizar nova intervençāo, face à situaçāo

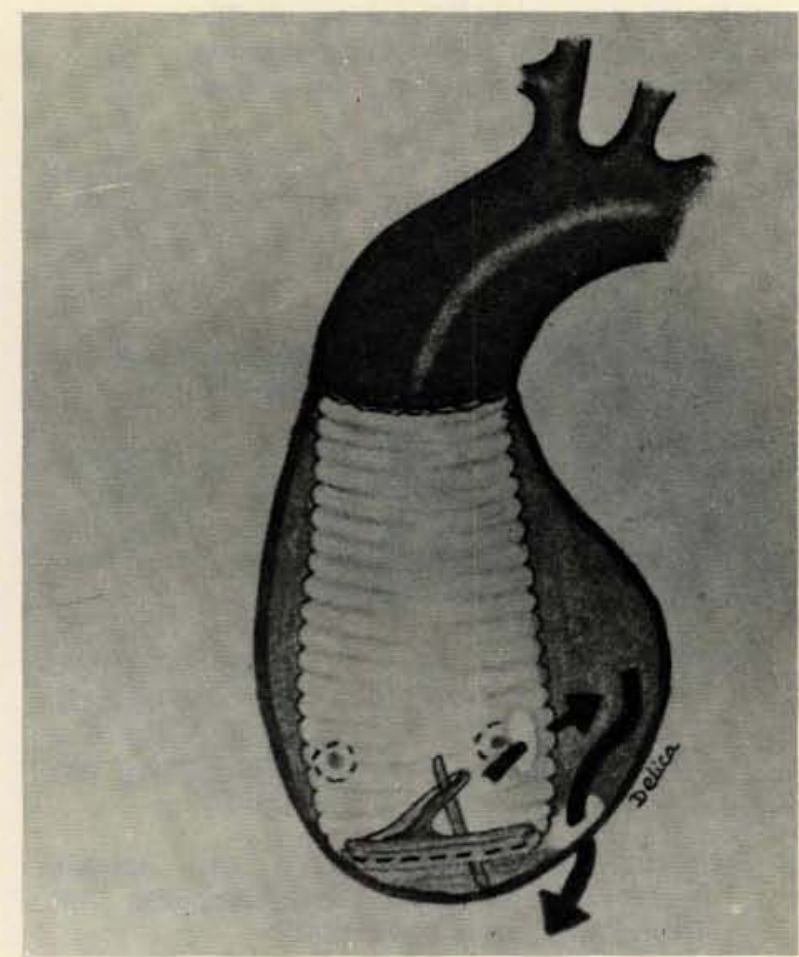

Fig. 5 - Representação esquemática dos defeitos encontrados no Caso 5. Deiscência nas suturas do óstio coronariano esquerdo e da anastomose proximal do enxerto, com pseudo-aneurisma e regurgitaçăo para o ventrículo esquerdo. clínica estável. Atualmente, 3 anos após a última cirurgia, encontra-se em classe funcional II, em uso de digital, diuréticos e anticoagulantes. Permanecem sinais de hemólise de grau leve.

\section{COMENTÁRIOS}

Embora não sejam freqüentes, complicaçōes tardias podem ocorrer após o implante de tubos valvulados pela técnica de BENTALL \& DE BONO '. Recentemente, BRITTON \& FOSTER ${ }^{2}$ descreveram método semelhante ao utilizado por nós, na substituição de bioprótese incluída em enxerto tubular, salientando a viabilidade e as vantagens dessa abordagem. Com base no conhecimento atual, entretanto, não se indica mais o uso de biopróteses em enxertos tubulares aórticos, salvo em situações especiais.

As deiscências de suturas, levando à formação de pseudo-aneurismas são situaçōes previstas, seja devido à fragilidade dos tecidos, seja por rotura tardia do próprio fio cirúrgico empregado. Na correção de deiscências, devem ser utilizados pontos separados, duplos, ancorados em feltros de Teflon ${ }^{3}$, sem necessidade de intervir no restante do enxerto.

Em certos casos, é percebida falta de endotelização do enxerto tubular, encontrado em algumas ocasiōes com a face interna totalmente desnuda, mesmo após mais de 1 ano do implante original. A formação de hematomas entre as paredes do enxerto e da aorta é sempre possível, tendo sido descrita como causa de compressão do tubo, ou de óstio coronariano ${ }^{4}$. Tal complicação não ocorreu na nossa experiência, embora, em 1 caso, houvesse espessa camada de hematoma organizado nesse espaço.

Devido ao turbilhonamento e à superfície rugosa do enxerto, algum grau de hemólise intravascular deve ser esperada. Em um de nossos casos, ocorreu grau significativo de hemólise (caso 5) por deiscência de suturas, levando-nos a indicar reoperação. A correção realizada não eliminou o problema, embora, reduzindo-o, tenha permitido uma evolução favorável do paciente.

Infecçōes em enxertos devem ser temidas e a profilaxia das mesmas, sempre enfatizada. Não tivemos caso de infecção externa como descrito por outros autores ${ }^{8}$, mas 2 reoperações foram devidas a endocardite infecciosa. A primeira por Aspergillus, já presente por ocasião da intervenção original, e outro caso por bactéria nāo identificada. Na nossa experiência, como sugerido por HARGROVE III \& EDMONDS Jr. ${ }^{8}$, a substituição da zona infectada do enxerto pode ser suficiente, não se recomendando intervir sobre áreas sadias, ou mesmo sobre as linhas de suturas, quando livres de infecção. 
KALIL, R. A. K.; GARCIA-MACEDO, R.; PRATES, P. R.; LUCCHESE, F. A.; SANTANN, J. R.; LARA, R. F. A.; COSTA, A. R.: DAUDT, N. S.; PEREIRA, E. M.; NESRALLA, I. A. - Reoperaçōes após cirurgia de Bentall-De Bono para ectasia ânulo-aórtica Rev. Bras. Cir. Cardiovasc., 3(2): 93-100, 1988.

Em resumo, o tratamento cirúrgico das complicaçōes tardias deve seguir condutas individualizadas para cada situação. Não se recomenda substituição radical de todo o enxerto. Ao contrário, a abordagem apenas da área comprometida parece levar a bons resultados. O risco é aceitável, acompanhado, geralmente, de evolução favorável a longo prazo. Profilaxia de endocardite infecciosa deve ser enfatizada. Biopróteses nāo devem ser empregadas, salvo em situações especiais, dada a possibilidade de degeneração tardia. A técnica do enxerto composto de tubo de Dacron com prótese valvular permanece como método de eleição para tratamento cirúrgico de ectasia ânulo-aórtica, apresentando resultados favoráveis a curto e longo prazo. A ocorrência de certo número de complicaçōes tardias nāo compromete suas vantagens, em relação a outras técnicas.

RBCCV 44205-54

KALIL, R. A. K.; GARCIA-MACEDO, R.; PRATES, P. R.; LUCCHESE, F. A.; SANT'ANNA, J. R.; LARA, R. F. A.; COSTA, A. R.; DAUDT, N. S.; PEREIRA, E. M.; NESRALLA, I. A. - Re-operations following Bentall-De Bono operation for anulo-aortic ectasia. Rev. Bras. Cir. Cardiovasc., 3(2): 93-100, 1988.

ABSTRACT: A major surgical problem is imposed when late complications occur in patients submitted previously to aortic root replacement by the Bentall-De Bono technique. During an 11 years period, from January 1976 to December 1986, 37 patients had aortic root replacement with valved conduits and 5 presented late complications (13.5\%) requiring a new operation. The lesions were: biological valve degeneration, infective endocarditis and suture leaks leading to pseudo aneurysm, peritubular leakage and hemolysis. There was 1 systemic embolization with an infected vegetation. The 5 patients were re-operated, with 1 surgical death $(20 \%)$, in a case presenting fungal endocarditis (Aspergillus), due to uncontroled bleeding. The remaining 4 had an uneventful hospital course. There was 1 late death during a surgical exploratory thoracic procedure. The remaining 3 patients enjoy a normal active life. One of these still has a small peritubular leakage causing mild aortic regurgitation and hemolysis. The surgical procedure consisted of Dacron tube replacement preserving the implanted valve prostheses in the 2 cases with infective endocarditis. Two ruptures biological valves were replaced by methalic disc valves. In this situation, the Dacron tubes were preserved and the valves approached through a longitudinal incision in the tube. The suture leaks were corrected with direct isolated mattress sutures. Late re-operations may be required after aortic root replacement with composite valve-tube grafts. They can be performed at an acceptable surgical risk. The technique should be as conservative as possible and directed to the causing lesions, preserving the remaining structures. A methalic prosthesis should be the first choice for the primary procedure, in order to avoid late tissue degeneration.

DESCRIPTORS: Bentall-De Bono operation, re-operation.

\section{REFERÊNCIAS BIBLIOGRÁFICAS}

1 BENTALL, H. \& DE BONO, A. - A technique for complete replacement of the ascending aorta. Thorax, 23(7): 338-339, 1968

2. BRITTON, L. W. \& FOSTER, E. D. - Replacement of a degenerated porcine valve within a composite aortic valve graft. Ann. Thorac. Surg., 43(5):568-569, 1987.

3. CRAWFORD, E. S. \& CRAWFORD, J. L. - Diseases of the aorta including an atlas of angiographic pathology and surgical technique. Baltimore, Williams and Wilkins, 1984.

4. CRAWFORD, E. S.; CRAWFORD, J. L.; SAFI, H. J.; COSELLI, J. S. - Reoperations for recurrent aneurysmal disease of the ascending aorta and transverse aortic arch. Ann. Thorac. Surg., 40(5): 439-455, 1985.

5. EYSTER, E.; ROTHCHILD, J.; MYCHJLIW, A. A. - Chronic intravascular hemolysis after aortic valve replacement: long-term study comparing different types of ball-valve prosthesis. Circulation, 44(3): 657-665 1971.

6. FERNANDES, P. M. P.; STOLF, N. A. G.; MOREIRA, L. F. P.; MADY, C.; VERGINELLI, G.; BARRETO, A. C. P.: JATENE, A. D. - Aneurismas e dissecçōes crônicas de aorta ascendente. Arq. Bras. Cardiol., 47(Supl. 1): 43, 1986. (Resumo).

7. GARCIA-MACEDO, R.; KALIL, R. A. K.; PRATES, P. R.; LUCHESE, F. A. SANT'ANNA, J. R.; PEREIRA, E. M.; COSTA, A. R.; LARA, R. F. A.; NESRALLA, I. A. Tratamento cirúrgico da ectasia ânulo-aórtica. Rev. Bras. Cir. Cardiovasc., 1(1): 44-48, 1966.

8. HARGROVE III, W. C. \& EDMONDS Jr., J. H. - Management of infected thoracic aortic prosthetic grafts. Ann. Thorac. Surg., 37(1): 72-77, 1984.

9. KALIL, R. A. K.; AZAMBUJA, P. C.; BERTOLETTI, V. E.; LUCHESE, F. A.; PRATES, P. R.; NESRALLA, I. A. - Surgical treatment of anulo-aortic ectasia with 
KALIL, R. A. K.; GARCIA-MACEDO, R.; PRATES, P. R.; LUCCHESE, F. A.; SANT'ANN, J. R.; LARA, R. F. A.: COSTA, A. R.;

DAUDT, N. S.; PEREIRA, E. M.; NESRALLA, I. A. - Reoperações após cirurgia de Bentall-De Bono para ectasia ânulo-aórtica. Rev. Bras. Cir. Cardiovasc., 3(2): 93-100, 1988.

composite grafts including homologous dura-máter valves. Ann. Thorac. Surg., 26(2): 142-148, 1978.

10. KOUCHOUKOS, N. T.; KARP, R. B.; LELL, W. A. - Replacement of the ascending aorta and aortic valve with a composite graft: results in 25 patients. Ann. Thorac. Surg., 24(2): 140-148, 1977.

\section{Discussão}

\section{DR. MAURO ARRUDA}

Recife, PE

Inicialmente, quero agradecer à Comissão Organizadora deste Congresso a oportunidade que me dá de comentar o trabalho do Dr. Renato Kalil, a quem cumprimento, e à sua equipe, pela excelência da apresentação. Recentemente, revimos, em nosso Serviço, 38 pacientes portadores de aneurisma da aorta; neste grupo, havia 16 aneurismas localizados na aorta ascendente; 9 eram representados por ectasia anular aórtica e 7 , dissecçōes, sendo 4 do tipo 1 e 3 do tipo 2; nestes pacientes com dissecções, foi, sempre, feita a correção da delaminação, interposição de enxerto tubular de Dacron e correção da delaminação, interposição de enxerto tubular de Dacron e correção da disfunção da valva; nos 9 pacientes portadores de ectasia anular aórtica, em 5 a correçăo foi feita implantando-se, em separado, uma prótese metálica tipo Starr-Edwards e um enxerto tubular de Dacron; em um outro paciente, a correção foi feita implantando-se uma prótese biológica de dura-máter, ressecção da zona extasiada e anastomose término-terminal da aorta. A técnica preconizada por Bentall-De Bono foi por nós realizada em 3 pacientes, 2 deles com boa evolução clínica e 1 terceiro que evoluiu para o óbito, tendo contribuído para esse óbito a distorção dos óstios coronarianos, sangramento após repetidas manobras para o seu alinhamento, revascularização dos troncos coronarianos com pontes de veia safena, resultando, daí, um prolongado tempo de perfusão, sangramento irreversível e óbito; a literatura está pontilhada de críticas a ambos os métodos; é referido que a operação de Bentall-De Bono favorece a distorção dos óstios coronarianos, que o tempo de perfusão é maior em função do maior número de anastomoses, que favorece a hemorragia, que favorece o escape paravalvar e paratubular, que favorece a formação de pseudo-aneurismas; por outro lado, criticas também são feitas à conduta do implante valvar e prótese tubular em separado, mais veementemente porque muito de tecido aórtico doente é preservado; curiosamente, nesta pequena série, a única registrada foi em um paciente que é comparado a 2 casos apresentados aqui; foi num paciente em que nós não escolhemos bem a prótese utilizada; a prótese escolhida foi uma válvula de duramáter, que, depois de 3 anos de implante, apresentou rotura do tecido com insuficiência aórtica e justamente num paciente em que nós haviamos ressecado a porçāo ectasiada da aorta e feito a anastomose terminal; a reoperação foi realizada sem problemas. Das complicaçōes descritas no trabalho do Renato, eu vejo, pelo que está descrito como complicaçōes da tecnica de Bentall-De Bono, que apenas o caso de número 5 se enquadra nessa gama de complicaçōes; os demais apresentados foram todos de complicaçōes inerentes à cirurgia cardiaca de um modo geral, referentes à escolha da prótese, à infecção; por esta razão, numa série tão bonita de casos operados e por ter apresentado apenas 1 caso de complicaçōes, que se enquadrou dentro das complicaçōes da técnica que o Renato escolheu, é que eu gostaria de voltar a cumprimentá-lo, pela excelência de seu trabalho. Muito obrigado.

\section{DR. HENRIQUE MURAD \\ Rio de Janeiro, RJ}

Eu gostaria, inicialmente, de agradecer a oportunidade de comentar este trabalho e, também, de parabenizar o Dr. Renato Kalil e o grupo de cardiologistas do Rio Grande do Sul, não só pelo magnífico trabalho apresentado, como também pelos resultados. As complicaçōes da técnica de Bentall-De Bono têm, cada vez mais, aparecido na literatura e o que mais se tem receio é o implante das coronárias; entretanto, apenas 1 caso mostrou alguma alteração nas coronárias, tardiamente; os demais casos referidos pelo Dr. Mauro Arruda foram por infecção, ou problemas de protese. O Dr. Kalil advoga que nós passemos a usar prótese metálica e nós temos o problema ao contrário; a nossa experiência é de cerca de 28 casos globais de pacientes com aneurisma de aorta ascendente, seja por dissecçāo, ou por ectasia ânulo-aórtica e nós temos o problema ao contrário; o paciente hipertenso em que trata de dissecção ânuloaórtica; \& tivemos casos de hemorragia cerebral tardia com o uso de anticoagulantes; então, também tivemos o uso da prótese metálica e, recentemente, passamos a usar as válvulas biológicas, na tentativa de não empregar anticoagulante nesses grupos de maior risco. (Slide) Então, a pergunta que existe, hoje, é se a cirurgia ideal seria, realmente, a de Bentall-De Bono para essas situaçōes, ou fazer a cirurgia que foi proposta pelo Dr. With e, depois, popularizada pelo Dr. Craig Miller, para os pacientes com dissecçōes aórticas, ou com ectasia ânulo-aórtica, e que os óstios coronarianos não fossem muito deslocados (slide), em que se deixam lingüetas onde ficam as coronárias e a ressecção aórtica é feita o mais baixo possível, praticamente perto do nivel do anel aórtico; deste modo, se resseca o tecido doente e se faz o implante da prótese ao nível das artérias coronárias. (Slide) Foi o que fizemos neste doente; foi quando conseguimos ter os melhores resultados imediatos e tardios em pacientes com dissecçōes aórticas agudas e, também, em casos de ectasia ânulo-aórtica, onde se resseca o aneurisma até o nível da valva aórtica, preservando 
KALIL, R. A. K.; GARCIA-MACEDO, R.; PRATES, P. R.; LUCCHESE, F. A.; SANT'ANN, J. R.; LARA, R. F. A.; COSTA, A. R.; DAUDT, N. S.; PEREIRA, E. M.; NESRALLA, I. A. - Reoperaçōes após cirurgia de Bentall-De Bono para ectasia ânulo-aórtica. Rev. Bras. Cir. Cardiovasc., 3(2): 93-100, 1988.

os óstios coronarianos, (slide) de tal modo que a prótese é implantada perto do anel aórtico e o óstio coronariano é mantido. Nós acreditamos que, talvez, possamos evitar, assim, os problemas trazidos com os óstios coronarianos, que tem sido muito descrito após a cirurgia de Bentall-De Bono. Gostariamos, finalmente, de parabenizar o grupo do Rio Grande do Sul.

\section{DR. NILZO RIBEIRO \\ Salvador, $B A$}

Eu tenho a impressão de que grande número de complicaçōes dessa cirurgia está na decorrência direta da linha de sutura do tubo do anel aórtico. (Slide) Os senhores reparem o seguinte: se nós deixarmos esta protuberância onde sai o óstio coronariano, é evidente que esta área de sutura será uma área problemática, difícil de co-habitar isto corretamente com o tubo; então, o que nós fizemos nos nossos 2 últimos doentes onde não tivemos nenhum sangramento, ficou uma sutura absolutamente estanque - colocamos o paciente em extracorpórea, levamos a ressecção da aorta até próximo do anel, desinserimos os óstios coronarianos, tanto o direito quanto o esquerdo, não ressecamos as válvulas aórticas, deixamos a válvula íntegra, pegamos um fio ancorado em feltro e entramos para a luz da aorta e, na saída, pegamos, novamente, a válvula aórtica; então, ficamos com um primeiro tecido, que era a parede da aorta, conjuntamente com o anel aórtico, pegamos a válvula da aorta e, agora, ficamos com as agulhas pelo lado de fora, pegamos este tubo, não fizemos tubo valvulado; tínhamos a prótese destacada, inteiramente solta do tubo e, agora, com estas agulhas que estavam colocadas pelo lado de fora, passamos, primeiro, no bordelete da prótese e, a seguir, no tubo, de tal maneira que, quando aproximamos este tubo, agora valvulado, contra o anel aórtico, tínhamos os seguintes planos, de fora para dentro: a plaquinha de feltro, a parede da aorta, o anel aórtico, a válvula, o bordelete da prótese e a parede do tubo. Se nós nos recordarmos da apresentação do Dr. Kalil, a maioria dos problemas ocorreu a partir desta linha de sutura e, como nós temos conhecimento de que o grande problema desta cirurgia é a hemorragia que se pode estabelecer ao nivel da sutura junto ao nível aórtico, aí reside o grande problema, o maior número de complicaçōes dessa cirurgia; uma outra coisa que nós não fazemos, e me dá a impressão de que deve ser uma coisa coerente, é envolver o tubo com a aorta, porque isto pode, no pós-operatório imediato, não permitir sangramento, mas permitir que, num pós-operatório mais tardio, o sangramento que ficou mascarado pelo envolvimento com a parede da aorta, dê esse tipo de problema apresentado pelo $\mathrm{Dr}$. Kalil. Muito obrigado.

\section{DR. RENATO KALIL (Encerrando)}

Agradeço os comentários dos Drs. Mauro Arruda, Henrique Murad e Nilzo Ribeiro. Procurando responder a todos, conjuntamente, gostaria de dizer que o título do nosso trabalho é "Reoperaçōes por complicaçōes após cirurgia de Bentall-De Bono"; pretendemos, com isto, apresentar casos de reoperaçōes e não casos de complicaçōes, como, talvez, tenha parecido. Achamos, ainda, apesar de se saber que existem outras técnicas, que esta de Bentall-De Bono, para este problema, é mais simples, mais rápida e mais completa para a correção deste defeito. Para resolver o problema do hematoma que se forma e foi, sobretudo, salientado pelo $\mathrm{Dr}$. Nilzo, existe a técnica da anastomose aorta com átrio direito, proposta na França, que tem sido usada, também, por alguns outros autores; nós nunca a utilizamos, mas talvez seja um recurso viável. Apenas, para finalizar, quero dizer que, em alguns casos, em situaçōes especiais em que se pode usar a válvula biológica, nós temos, atualmente, utilizado o tubo preparado no I.M.C., de pericárdio bovino, pelo resultado imediato muito mais fácil e mais adequado, com melhor hemostasia, restando, apenas, o óbice dele conter uma prótese biológica. Muito obrigado. 